\title{
Reducing Colorectal Cancer Incidence and Disparities: Performance and Outcomes of a Screening Colonoscopy Program in South Carolina
}

\author{
Sudha Xirasagar, ${ }^{1}$ Yi-Jhen Li, ${ }^{1}$ James B. Burch, ${ }^{2,3,4}$ Virginie G. Daguisé, ${ }^{5}$ \\ Thomas G. Hurley, ${ }^{2}$ and James R. Hébert ${ }^{2,3}$ \\ ${ }^{1}$ Department of Health Services Policy and Management, University of South Carolina, Arnold School of Public Health, \\ 915 Greene Street, Columbia, SC 29208, USA \\ ${ }^{2}$ South Carolina Statewide Cancer Prevention \& Control Program, University of South Carolina, 915 Greene Street, \\ Columbia, SC 29208, USA \\ ${ }^{3}$ Department of Epidemiology and Biostatistics, University of South Carolina, Arnold School of Public Health, \\ 915 Greene Street, Columbia, SC 29208, USA \\ ${ }^{4}$ WJB Dorn Department of Veterans Affairs Medical Center, 6439 Garners Ferry Road, Columbia, SC 29209-1639, USA \\ ${ }^{5}$ Division of Cancer Prevention and Control, South Carolina Department of Health and Environmental Control, \\ 2100 Bull Street, Columbia, SC 29201, USA
}

Correspondence should be addressed to Sudha Xirasagar; sxirasagar@sc.edu

Received 9 February 2014; Revised 23 May 2014; Accepted 27 May 2014; Published 23 June 2014

Academic Editor: Haiying Chen

Copyright (C) 2014 Sudha Xirasagar et al. This is an open access article distributed under the Creative Commons Attribution License, which permits unrestricted use, distribution, and reproduction in any medium, provided the original work is properly cited.

This study evaluated the efficiency, effectiveness, and racial disparities reduction potential of Screening Colonoscopies for People Everywhere in South Carolina (SCOPE SC), a state-funded program for indigent persons aged 50-64 years (45-64 years for African American (AA)) with a medical home in community health centers. Patients were referred to existing referral network providers, and the centers were compensated for patient navigation. Data on procedures and patient demographics were analyzed. Of 782 individuals recruited $(71.2 \%$ AA), $85 \%$ (665) completed the procedure (71.1\% AA). The adenoma detection rate was $27.8 \%$ (males $34.6 \%$ and females $25.1 \%$ ), advanced neoplasm rate $7.7 \%$ (including 3 cancers), cecum intubation rate $98.9 \%$, inadequate bowel preparation rate $7.9 \%$, and adverse event rate $0.9 \%$. All indicators met the national quality benchmarks. The adenoma rate of $26.0 \%$ among AAs aged 45-49 years was similar to that of older Whites and AAs. We found that patient navigation and a medical home setting resulted in a successful and high-quality screening program. The observed high adenoma rate among younger AAs calls for more research with larger cohorts to evaluate the appropriateness of the current screening guidelines for AAs, given that they suffer $47 \%$ higher colorectal cancer mortality than Whites.

\section{Introduction}

There is wide variation across population subgroups in cancer incidence, mortality, or both. Nationally in the United States of America, African Americans (AAs) have $\approx 17 \%$ higher colorectal cancer $(\mathrm{CRC})$ incidence and $\approx 47 \%$ higher mortality than Whites [1]. AAs also are diagnosed at younger ages, on average and with later-stage disease, have a higher incidence before the recommended screening age of 50 years, and tend to have worse prognoses even after accounting for other factors [2,3]. These disparities tend to be much larger in South Carolina (SC) than in the US average $[4,5]$.

The majority of CRCs in average-risk individuals arise from the polyp-to-cancer pathway, which translates into an opportunity to prevent cancers by removing polyps detected through screening age-appropriate adults. Of all cancer screening tests, colonoscopy is the most effective both for early detection and, more importantly, for primary prevention of CRC because it enables removal of precancerous polyps before they turn cancerous. Colonoscopy has some 
disadvantages, however. It requires specially trained physicians and is expensive and invasive, requiring a well-equipped and well-staffed facility for safe, high-quality performance. Consequently, health insurance remains a key determinant of colonoscopy screening completion, which currently stands at $19.1 \%$ among working-age uninsured adults in the 2010 National Health Interview Survey Data, compared to $56.7 \%$ among those privately insured [6]. Despite many uninsured individuals having primary care access through the ambulatory care safety net, mainly federally qualified health centers (FQHC), the colonoscopy rate among this subgroup is low, about 24\% [7], because FQHCs cannot obtain adequate volumes of charity colonoscopy care.

SC has the 16th highest percentage of uninsured adults in the USA [8] and has a higher proportion of AA population $(30 \%)$ than the national average. The program, Screening Colonoscopies for People Everywhere in South Carolina (SCOPE SC), was designed to leverage the medical home relationship of FQHCs with uninsured individuals. A sum of \$1 million was authorized by the South Carolina Legislature for the Department of Health and Environmental Control (SCDHEC) to cover screening colonoscopy of average-risk established FQHC patients $\geq 50$ years old ( $\geq 45$ years for AAs) with income $\leq 200 \%$ of poverty and without private or Medicaid insurance. Based on studies showing that patient navigation improves colonoscopy completion rates $[9,10]$, the program asked participating FQHCs to use their existing colonoscopy referral channels and funded patient navigation services to maximize screening completion and other facilitation services. The SCDHEC program office organized referrals and follow-up care for individuals who experienced a complication or were diagnosed with cancer.

About 800 screening procedures were targeted, based on an average cost of $\$ 1,000$ each (covering provider reimbursement at Medicare rates, patient navigation, and program evaluation). Provider reimbursements were contingent upon reporting to the program, thus allowing for monitoring of procedure quality and completeness. At the end of year 1, SCDHEC assigned the program performance evaluation to an external academic research team, the results of which are presented in this paper.

\section{Methods}

Four FQHC sites participated in the SCOPE SC program, having been identified based on elevated CRC incidence, mortality, and late-stage CRC rates; resources and infrastructure; and a geographic distribution pattern providing for statewide representation. The program was promoted via direct notification of FQHC staff and outreach workers through promotional materials (postcards and posters) and by including the program on the American Cancer Society's toll-free telephone hotline. Eligible individuals included current FQHC patients with current SC residency, US citizenship (established with the social security number), no health insurance, income $\leq 200 \%$ of the federal poverty limit, age eligible (50-64 years for Whites without a CRC family history, 45-49 years for Whites with CRC family history, and 45-64 years for AAs regardless of family history), no gastrointestinal symptoms, and not being up to date with CRC screening per published guidelines (Figure 1). All beneficiaries were referred to by their primary care physician at a participating FQHC. If not a current FQHC patient, they were required to enroll as patients for purposes of adequate care and referral for complications, cancer diagnosis and/or follow-up surveillance.

Each FQHC had at least one navigator dedicated to the program. Eligible patients were identified by the primary physician and referred to the navigator for obtaining preauthorization from SCDHEC program staff. The patient then received a bowel preparation kit that included written instructions, and the procedure was scheduled. Navigators included FQHC nurses or administrative staff who routinely interacted with patients. FQHCs were compensated for navigation, \$25 for the initial referral and associated paperwork and $\$ 75$ for successful completion of the procedure. SCOPE SC program staff provided one-on-one training to navigators and FQHC staff administering the program. The training consisted of several hours of instruction emphasizing the importance of an adequate bowel preparation including detailed instructions for patients, methods to help patients plan for their procedure (e.g., obtaining transportation and other care-related advice), and details on program administration, referrals, and other resources.

As a condition of reimbursement, participating FQHCs, endoscopy clinics, FQHCs, and laboratory service providers submitted standard forms on all eligible individuals referred for colonoscopy. Data collected included demographic, relevant family and personal medical history (submitted by FQHCs), clinical procedure and polyp information (by colonoscopy providers), and polyp histopathology features (by laboratory service providers). SCDHEC established a medical quality assurance committee consisting of community-based, SCDHEC, and academic physicians that monitored procedure quality throughout the year by periodically reviewing the clinical and pathology data for all cases submitted by providers. When suboptimal outcomes were identified (low polyp detection rate, poor bowel preparation rate, or placing multiple polyps from different colorectal segments in a single jar), potential causes were discussed by the committee and feedback communicated to providers through the SCOPE SC program manager.

The study sample consisted of year I data on all screening colonoscopies provided during fiscal year 2009-10 (July 1 through June 30). The study team systematically reviewed the data files compiled from the patient referral, screening, and laboratory forms together against the original patient forms for accuracy and entered missing/discrepant data. Data entry was completed onsite within the SCDHEC data system. Files were linked, deidentified, and extracted in Excel format into University of South Carolina (USC) computers. The study was approved by the USC and SCDHEC Institutional Review Boards.

Univariate statistics (and chi-square tests where applicable) are used to present the program's efficiency (in outreach and procedure completion), beneficiary demographics, disparity populations reached, procedure effectiveness (cecum 


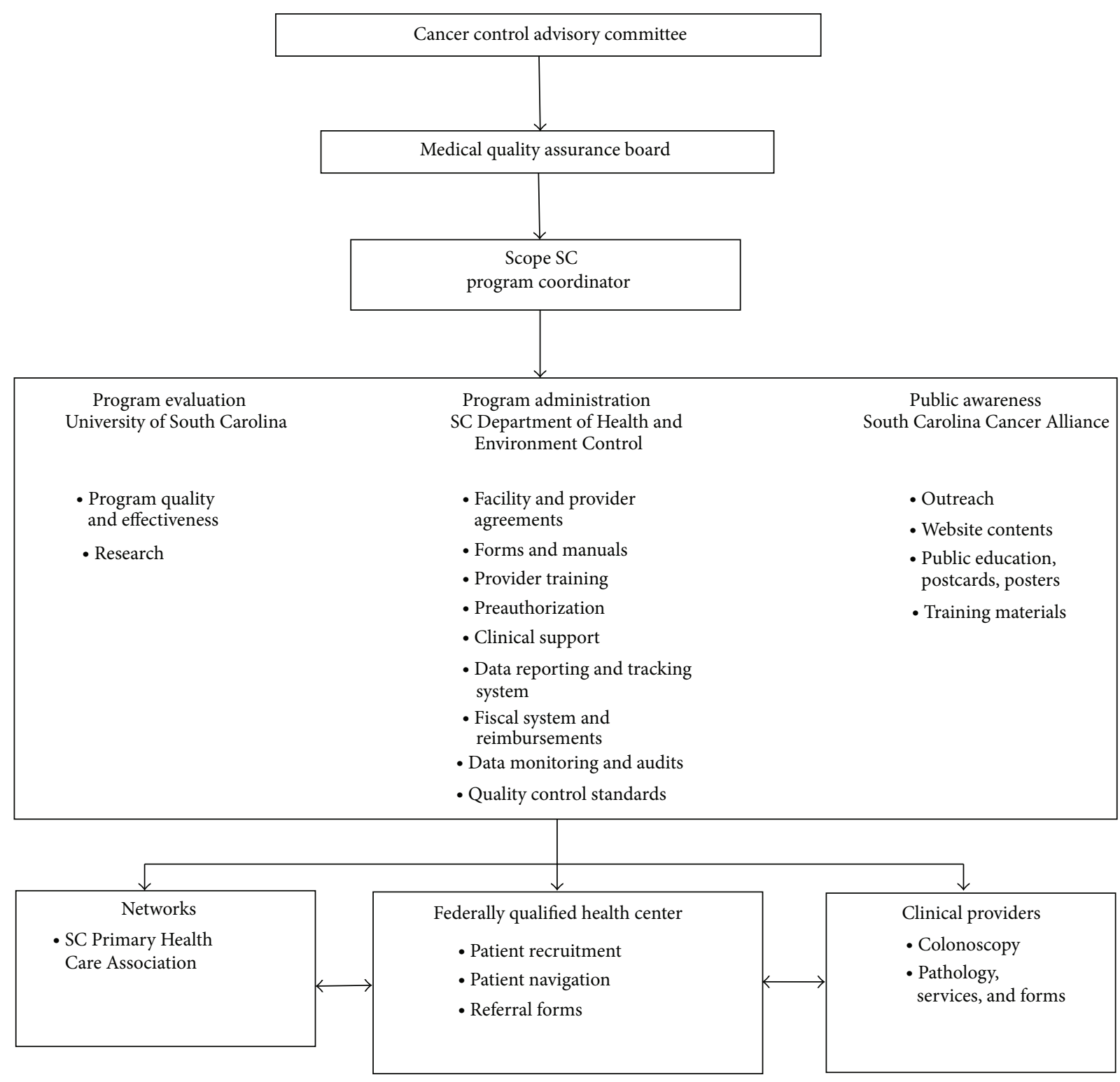

FIGURE 1: SCOPE SC program organization chart.

intubation, polyp detection and retrieval, adenoma, advanced neoplasm, and cancer detection rates), bowel preparation quality, and patient safety (adverse event rate). SAS version 9.2 was used.

\section{Results}

Table 1 summarizes the SCOPE SC year 1 program performance on efficiency, effectiveness, and patient safety. Of 782 eligible beneficiaries identified by the four participating FQHCs, 665 (85\%) completed the procedure. The unadjusted cecum intubation rate was $98.1 \%$ (the US Multisociety Task Force (USMSTF), adjusted cecal intubation rate was $98.6 \%$, excluding unintubated cases due to poor bowel preparation) [11], and the circumstance-adjusted cecum intubation rate was $98.9 \%$ (excluding unintubated cases due to poor bowel preparation and medical reasons requiring procedure termination) [12]. All rates, including the unadjusted rate, exceeded the USMSTF benchmark of 95\% [11].

The polyp detection rate was $56.4 \%$ (proportion of screened persons with $\geq 1$ polyp detected). The adenoma detection rate (having any polyp with an adenomatous or carcinomatous histology, excluding hyperplastic polyps and normoplastic or lymphoid tissue) was $27.8 \%$ overall, $34.6 \%$ for men and 25.1\% for women. Both rates exceed the USMSTF minimum standards of $>25 \%$ for men and $>15 \%$ for women [11]. The advanced neoplasm detection rate (adenomas $\geq 10 \mathrm{~mm}$, villous/tubulovillous adenomas, high-grade dysplasia, or cancer) was $7.7 \%$ overall, $9.9 \%$ in men and $6.8 \%$ among women. Three cancer cases were found, $0.4 \%$ of those were screened. No benchmark exists for advanced neoplasm detection [11], although the USMSTF notes a documented 
TABLE 1: SCOPE SC program performance in year 1: efficiency of patient recruitment, effectiveness of procedure performance, and patient safety.

\begin{tabular}{|c|c|}
\hline Performance indicator & Number $\%$ \\
\hline \multicolumn{2}{|l|}{ Program efficiency } \\
\hline Program target number of colonoscopy screenings (funding available) & 800 \\
\hline Number of eligible beneficiaries identified & 782 \\
\hline Number of who completed colonoscopy & 665 \\
\hline$\%$ of eligible beneficiaries navigated through procedure completion & $85 \%$ \\
\hline Number of performing physicians & 32 \\
\hline Bowel preparation status documented (benchmark 100\%) [12] & $98.5 \%$ \\
\hline Patient safety: adverse event rate (benchmark 2\%, all event types) [12] & $0.9 \%^{*}$ \\
\hline \multicolumn{2}{|l|}{ Procedure performance quality } \\
\hline Cecal intubation rate (benchmark 95\%) [12] & $98.9 \%$ \\
\hline Bowel preparation status rated fair, good, or excellent & $92.1 \%$ \\
\hline Proportion of screened persons with polyp(s) & $56.4 \%$ \\
\hline Proportion of polyps completely removed & $93.1 \%^{* *}$ \\
\hline Proportion of polyps retrieved for pathology exam (benchmark 95\%) [11] & $99.9 \%$ \\
\hline \multicolumn{2}{|l|}{ Polyp, adenoma, and cancer detection } \\
\hline Proportion of screened persons with polyp(s) & $56.4 \%{ }^{* *}$ \\
\hline Proportion of screened persons with hyperplastic polyp(s) & $34.6 \%{ }^{* *}$ \\
\hline Proportion of screened persons with adenoma(s) found (ADR) (benchmark $15 \%$ for women and $25 \%$ for men) [12] & $27.8 \%$ \\
\hline Proportion with advanced neoplasm removed (cancer and polyps at imminent risk of cancer) & $7.7 \%{ }^{* *}$ \\
\hline Diagnosed with colorectal cancer & $3(0.45 \%)$ \\
\hline Total number of polyps removed & 917 \\
\hline Total number of adenomas removed & 338 \\
\hline Total number of advanced neoplasms removed & 58 \\
\hline
\end{tabular}

Advanced neoplasms include adenomas $\geq 10 \mathrm{~mm}$ in diameter, adenomas with villous or tubule villous features or high-grade dysplasia, and cancer or carcinoid tumor.

${ }^{*} n=6$ (1) bleeding, (2) incomplete colonoscopy due to torsion, and (3) unspecified but having good bowel preparation and the procedure was completed, no perforations.

${ }^{* *}$ No national quality benchmarks exist for these indicators.

range of $3-10 \%$ [11] in US colonoscopy cohorts. The SCOPE $\mathrm{SC}$ rate is close to the upper end of the documented range.

Adverse events were documented in $0.9 \%$ of procedures, within the benchmark limit ( $n=6$ cases, (1) bleeding, (2) incomplete colonoscopy due to torsion, and (3) unspecified but having good bowel preparation and the procedure was completed, no perforations). The USMSTF benchmarks are $<1 / 300$ case of sedation-related complications requiring endotracheal intubation or mask ventilation, $<1$ bowel perforation per 1000 procedures, and $<1 / 100$ major postpolypectomy bleeding [11]. Documentation of bowel preparation status was available for $98.5 \%$ of recipients $(655$ out of 665), slightly lower than the benchmark of $100 \%$ [11]. Bowel preparation status is important for maximizing polyp detection $[13,14]$, and poor bowel preparation may trigger cancellation of the procedure. Therefore adequate bowel contributes to the cancer protection effectiveness of colonoscopy [15]. Bowel preparation status was good or excellent in $69.3 \%$, fair in $22.7 \%$, and poor in $7.9 \%$ of the patients. The nationwide rate of poor preparation is $25 \%$ [14]. There are no USMSTF benchmarks for rates of good/poor bowel preparation although a benchmark exists for the rate of documentation of bowel preparation status (100\%).
Of a total of 917 polyps found, 916 (99.9\%) were retrieved for pathological examination (benchmark 95\%) [11]. A total of 338 adenomas (including advanced neoplasms) were removed among the 665 patients, for an average of 0.51 adenomas per subject screened. Of these, 58 (0.09 per subject screened) were advanced neoplasms. There are no benchmarks established for the mean number of adenomas per screened subject. Three cancer cases were found at colonoscopy, two cancers located in the rectum and one in the sigmoid colon. Of 55 advanced adenomas, $76.4 \%$ were $10 \mathrm{~mm}$ or more in diameter, $16.4 \%$ had villous or tubulovillous features, and 5.5\% showed high grade dysplasia. Additionally, there were 8 serrated adenomas. Among the 45-49-year-old AAs, 6 had advanced adenomas.

Table 2 shows the demographic characteristics of beneficiaries, the adenoma rate, and advanced neoplasm rate among the demographic subgroups. Most beneficiaries were female (71.1\%), African American (71.1\%), and lived in the Midlands region of SC (75.3\%). The mean age was 55.2 (SD = 4.9) years, and majority (64.4\%) were aged 50-59 years. The adenoma detection rate among males was $34.6 \%$, and among females $25.1 \%(P=0.01)$. The rate was $26.0 \%$ among those $45-49$ years old (all AA), $28.4 \%$ in the $50-59$ year age 
TABLE 2: SCOPE SC beneficiary demographics and corresponding adenoma detection rates $(n=665)$.

\begin{tabular}{|c|c|c|c|}
\hline & Number of beneficiaries & Adenoma detection rate & $\begin{array}{c}\text { Advanced neoplasm } \\
\text { detection rate }\end{array}$ \\
\hline \multicolumn{4}{|l|}{ Geographic region } \\
\hline Upstate & $142(21.5 \%)$ & $38 / 141(27.0 \%)$ & $16 / 141(11.3 \%)$ \\
\hline Midlands & $501(75.3 \%)$ & $140 / 498(28.1 \%)$ & $33 / 498(6.6 \%)$ \\
\hline Low country & $22(3.3 \%)$ & $6 / 22(27.3 \%)$ & $2 / 22(9.1 \%)$ \\
\hline \multicolumn{4}{|l|}{ Patients } \\
\hline \multicolumn{4}{|l|}{ Gender } \\
\hline Male & $192(28.9 \%)$ & 66/191 (34.6\%) & 19/191 (9.9\%) \\
\hline Female & $473(71.1 \%)$ & $118 / 470(25.1 \%)$ & $32 / 470(6.8 \%)$ \\
\hline \multicolumn{4}{|l|}{ Race $^{*}$} \\
\hline White & $164(24.9 \%)$ & $51 / 163(31.3 \%)$ & $17 / 163(10.4 \%)$ \\
\hline Black & $468(71.1 \%)$ & $123 / 465(26.5 \%)$ & $31 / 465(6.7 \%)$ \\
\hline Other & $26(4.0 \%)$ & $5 / 26(19.2 \%)$ & $2 / 26(7.7 \%)$ \\
\hline \multicolumn{4}{|l|}{ Age (years) ${ }^{* *}$} \\
\hline $45-49^{* * *}$ & $77(11.6 \%)$ & $20 / 77(26 \%)$ & 6/77 (7.8\%) \\
\hline $50-59$ & $426(64.4 \%)$ & $120 / 423(28.4 \%)$ & $35 / 423(8.3 \%)$ \\
\hline $60-64$ & $159(24.0 \%)$ & $43 / 158(27.2 \%)$ & 9/158 (5.7\%) \\
\hline \multicolumn{4}{|l|}{ Family history } \\
\hline Yes & $85(12.8 \%)$ & $25 / 85(29.4 \%)$ & $9 / 85(10.6 \%)$ \\
\hline No or missing ${ }^{* * * *}$ & $580(87.2 \%)$ & $159 / 576(27.6 \%)$ & $42 / 576(7.3 \%)$ \\
\hline
\end{tabular}

Note: denominators for adenoma and advanced neoplasm detection rate vary due to missing data.

${ }^{*}$ Race information was missing for 7 patients.

${ }^{* *}$ Age information was missing for 1 patient.

${ }^{* * *}$ Includes 14 Whites screened due to a family history of colorectal cancer.

${ }^{* * * *}$ Question design did not permit distinction between absence of family history and nonresponse.

group, and $27.2 \%$ in the $60-64$ age group $(P=0.89)$. When examined by race, $31.3 \%$ of Whites, $26.5 \%$ of AAs, and $19.2 \%$ of other race/ethnicities had $\geq 1$ adenoma $(P=0.31)$. There was no significant difference in adenoma rates by geographic region. AAs aged 45-49 years were as likely as older Whites and AAs (aged over 50 years) to have an adenoma after controlling for gender $(P=0.56)$.

Table 3 presents the performance of SCOPE SC in addressing racial disparities in CRC. Of screening-eligible beneficiaries recruited at the FQHCs, 71.2\% were AA. Among those who completed colonoscopies, $71.1 \%$ were AA. The adenoma detection and advanced neoplasm detection rates are also presented.

\section{Discussion}

There is little documentation of state-funded CRC screening programs for the indigent, particularly statewide programs emphasizing colonoscopy as the primary screening test. One study documented the program design and beneficiary profile of Louisiana's state-funded screening program that offered fecal immunochemical testing (FIT) to the medically indigent attending FQHCs followed by colonoscopy for those with abnormal FIT tests [16]. The State of Delaware has implemented a colonoscopy-based screening program for the uninsured since 2002. Its performance and outcomes up to
2009 are documented [17]. By 2009 the program had wiped out racial disparities in screening (74\% of AAs and Whites being up to date with CRC screening in the BRFSS 2009 data, of which $85 \%$ was accounted for by colonoscopy screening in both racial groups). Similar to the Delaware program the SCOPE SC program chose to fund primary colonoscopy screening in view of low (per test) sensitivity of FIT for CRC prevention [18]. In the SC program $85 \%$ of 782 persons who were recruited completed the screening colonoscopy procedure compared to $66 \%$ of 975 persons recruited for the FIT procedure in Louisiana, despite the significantly invasive and therefore potentially intimidating nature of colonoscopy relative to FIT.

The design and performance of the SCOPE SC program in year 1 were consistent with the US Healthy People 2020 goal of "health equity, elimination of disparities and improving the health of all groups" by "facilitating high-quality, longer lives, free of preventable disease, disability, injury and premature death" [19]. The Healthy People 2010 goal of reducing CRC mortality to $13.9 / 100,000$ [19] remained far beyond reach (current rate 21.9/100,000) [1], partly due to disproportionately high CRC mortality among AAs [20] (47\% higher than among Whites). In the SCOPE SC program $71 \%$ of beneficiaries were AA, and the mean beneficiary age was 55.2 years. All of these features are encouraging. Considering the potential for cumulative cancer mortality gain, the mean 
TABLE 3: SCOPE SC performance in addressing racial disparities in colorectal cancer.

\begin{tabular}{lcccc}
\hline Race/ethnicity & $\begin{array}{c}\text { Eligible beneficiaries } \\
\text { recruited }\end{array}$ & $\begin{array}{c}\text { Percent completed } \\
\text { colonoscopy }\end{array}$ & $\begin{array}{c}\text { Percent with adenomas } \\
\text { found }\end{array}$ & $\begin{array}{c}\text { Percent with advanced } \\
\text { neoplasms }\end{array}$ \\
\hline African American & 493 & $468(95.0 \%)$ & $123(26.3 \%)$ & $31(6.6 \%)$ \\
White & 172 & $164(95.3 \%)$ & $51(31.1 \%)$ & $17(10.4 \%)$ \\
Other/missing & 117 & $33(28.2 \%)$ & $10(30.3 \%)$ & $3(9.1 \%)$ \\
\hline Total & 782 & $665(85.0 \%)$ & $184(27.7 \%)$ & $51(7.7 \%)$ \\
\hline
\end{tabular}

beneficiary age was close to the recommended screening commencement age of 50 years, indicating that SCOPE SC gave the beneficiary cohort an early start for optimal preventive benefit, with more potential life years saved than would be the case if the mean age were higher. A high proportion of AA among beneficiaries served (71\% compared to the state's overall AA population of $29 \%$ ) indicates that SCOPE SC succeeded in focusing more resources on this high-disparity group. Equal proportions of screening-eligible AAs and Whites recruited actually completed the procedure. Of the AA population in SC $51.3 \%$ live below $200 \%$ of poverty compared to $31.4 \%$ of Whites [21]. The screening coverage advantage that was achieved for AAs relative to Whites is consistent with the performance of Delaware's statewide screening program for the medically indigent implemented from 2002 to 2011. The Delaware program achieved a $100 \%$ reduction in colonoscopy screening disparities between AAs and Whites [17]. One study limitation is the lack of information on the reasons/barriers for completion of the procedure among those who did not complete the procedure.

Almost $12 \%$ of beneficiaries were AAs aged 45-49 years. Unexpectedly, we found that the adenoma rate and advanced neoplasm rate in this age group were similar to the rates found among older Whites and AA. A study limitation is that potential recruitment bias favoring those with a family history among younger AAs cannot be ruled out. Although the patient referral form had a question on family history, the design was such that nonresponse could not be distinguished from those without a family history. However the frequency of adenomas was not different among those with a family history of CRC (Table 2).

Our finding suggests that SCOPE SC's innovation of extending coverage to AAs aged 45-49 years is justified and is consistent with the American College of Gastroenterology recommendations [22], earlier than the American Cancer Society's recommended screening age of 50 years uniformly for all racial groups [23]. Currently almost no insurance plan covers screening prior to 50 years of age. Our findings emphasize the need for further research with larger cohorts to verify the evidence for changing the screening eligibility age for AAs. On another note, the preponderance of women (71\%) among SCOPE SC beneficiaries indicates that more focused efforts to recruit males are needed.

Provider engagement and influence on patients' decisions to undergo elaborate colon preparation are facilitated by an established doctor-patient relationship, usually not an option for uninsured patients relying on episodic charity care received from sporadically available providers in emergency rooms and free clinics. Because FQHCs serve as a primary care medical home for the uninsured, they present an opportune setting for colonoscopy screening programs targeting the medically indigent. The SCOPE SC program chose to deploy FQHCs as the patient recruiting sites and provided funds to cover colonoscopy costs and patient navigation, which yielded highly encouraging results: rapid accrual of targeted beneficiaries, very high procedure completion rate of $85.0 \%$, and high rates of acceptable bowel preparation. The critical role of patient navigation in improving bowel preparation and adenoma detection is well documented [24-26]. The procedure completion rate of $85 \%$ exceeds the documented rate of $66 \%$ following structured patient navigation efforts in New York City [9] and is similar to a recently documented rate of $91 \%$ colonoscopy completion following a comprehensive patient navigator program in $\mathrm{New}$ York City [27].

Despite meeting or exceeding the USMSTF benchmark rates for cecum intubation, polyp retrieval, and adenoma detection, the cohort had a suboptimal bowel preparation rate (considering fair and poor preparation) of 30.6\%, which is consistent with the $34 \%$ rate achieved in a Medicaid primary care clientele in New York City by implementing comprehensive patient navigation services [27]. The cohort's $7.9 \%$ rate of poor bowel preparation (which causes cancellation of the procedure and sometimes termed as "inadequate preparation" [27]) is much lower than the national average of $25 \%$ [14]. The higher rate of adequate bowel preparation for the cohort is attributable, at least in part, to the detailed data collection system coupled with ongoing quality monitoring and feedback by an expert panel, instead of the widely prevalent practice of after-the-fact program evaluation typical of most programs. Three cancer cases were detected and referred for treatment. All were asymptomatic patients. Cancer stage information is not available.

In conclusion, year 1 of the SCOPE SC program served as a successful pilot validation of the program's innovative design elements: leveraging the medical home relationships of the uninsured with FQHCs, purposive funding of patient navigation, and extending coverage to AA aged 45-49 years. Results show that high completion rates can be achieved within an ad hoc program's fiscal year timeline. The program design enabled scarce dollars to selectively reach out to populations with the greatest need, thereby maximizing the program's potential contribution to the healthy people 2020 goal for reducing overall CRC mortality. Expansion of earmarked appropriations for colonoscopy screening of the medically indigent in SC makes sound economic sense as 
the state and federal governments stand to reap Medicaid and Medicare cost savings on CRC treatment in later years. Appropriations should be linked to a structured quality management system via establishment of provider accountability systems that track performance against quality indicators.

The relatively high rate of adenomas and advanced neoplasms among AAs aged 45-49 years is both intriguing and potentially very important. Given the increased probability of more aggressive disease at younger ages [28], this has major implications for policy and practice aimed at reducing racial disparities in CRC incidence and mortality. This result calls for further investigation with larger screening cohorts.

$\begin{array}{ll}\text { Abbreviations } \\ \text { CRC: } & \text { Colorectal cancer } \\ \text { FIT: } & \text { Fecal immunochemical testing } \\ \text { FQHC: } & \text { Federally qualified health centers } \\ \text { SC: } & \text { South Carolina } \\ \text { SCDHEC: } & \text { South Carolina Department of Health and } \\ & \text { Environmental Control } \\ \text { SCOPE SC: } & \text { Screening Colonoscopies for People } \\ & \text { Everywhere in South Carolina } \\ \text { US: } & \text { United States } \\ \text { USC: } & \text { University of South Carolina } \\ \text { USMSTF: } & \text { US Multisociety Task Force. }\end{array}$

\section{Disclosure}

The content is solely the responsibility of the authors and does not necessarily represent the official view of the National Cancer Institute or the National Institutes of Health.

\section{Conflict of Interests}

The authors declare that there is no conflict of interests regarding the publication of this paper.

\section{Acknowledgments}

The authors acknowledge Sonya Younger, MBA, Program Manager of the SCOPE SC Program, for her role in program management and data collection. This work was supported by four Grants, Contract no. CY-11-032 SCOPE SC Colonoscopies-Quality Indicators and Equity of Participant Referrals (PI: S Xirasagar) from the South Carolina Department of Health and Environmental Control, Grant no. 1R15CA156098-01 (PI: S Xirasagar) awarded by the National Cancer Institute, Grant no. 3U48DP001936, South Carolina Cancer Prevention and Control Research Network (JR Hebert, P.I.) from the Centers for Disease Prevention and Control, and K05 CA136975, an Established Investigator Award in Cancer Prevention and Control from the Cancer Training Branch of the National Cancer Institute to JR Hébert.

\section{References}

[1] B. K. Edwards, E. Ward, B. A. Kohler et al., "Annual report to the nation on the status of cancer, 1975-2006, featuring colorectal cancer trends and impact of interventions (risk factors, screening, and treatment) to reduce future rates," Cancer, vol. 116, no. 3, pp. 544-573, 2010.

[2] J. J. Fenton, D. J. Tancredi, P. Green, P. Franks, and L.-M. Baldwin, "Persistent racial and ethnic disparities in up-to-date colorectal cancer testing in medicare enrollees," Journal of the American Geriatrics Society, vol. 57, no. 3, pp. 412-418, 2009.

[3] US Cancer Statistics Working Group 2011, http://apps.nccd.cdc .gov/uscs/.

[4] V. G. Daguise, J. B. Burch, M.-J. Horner et al., "Colorectal cancer disparities in South Carolina: descriptive epidemiology, screening, special programs, and future direction," Journal of the South Carolina Medical Association, vol. 102, no. 7, pp. 212-220, 2006.

[5] J. R. Hébert, V. G. Daguise, D. M. Hurley et al., "Mapping cancer mortality-to-incidence ratios to illustrate racial and sex disparities in a high-risk population," Cancer, vol. 115, no. 11, pp. 2539-2552, 2009.

[6] J. A. Shapiro, C. N. Klabunde, T. D. Thompson, M. R. Nadel, L. C. Seeff, and A. White, "Patterns of colorectal cancer test use, including CT colonography, in the 2010 National Health Interview Survey," Cancer Epidemiology Biomarkers and Prevention, vol. 21, no. 6, pp. 895-904, 2012.

[7] M. Lopez-Class, G. Luta, A.-M. Noone et al., "Patient and provider factors associated with colorectal cancer screening in safety net clinics serving low-income, urban immigrant Latinos," Journal of Health Care for the Poor and Underserved, vol. 23, no. 3, pp. 1011-1019, 2012.

[8] U.S. Census Bureau 2010, http://www2.census.gov/library/publications/2008/demo/p60-235/p60no235_table8.pdf.

[9] L. A. Chen, S. Santos, L. Jandorf et al., "A program to enhance completion of screening colonoscopy among urban minorities," Clinical Gastroenterology and Hepatology, vol. 6, no. 4, pp. 443450, 2008.

[10] J. Christie, S. Itzkowitz, I. Lihau-Nkanza, A. Castillo, W. Redd, and L. Jandorf, "A randomized controlled trial using patient navigation to increase colonoscopy screening among low-income minorities," The Journal of the National Medical Association, vol. 100, no. 3, pp. 278-284, 2008.

[11] D. K. Rex, J. H. Bond, S. Winawer et al., "Quality in the technical performance of colonoscopy and the continuous quality improvement process for colonoscopy: recommendations of the U.S. Multi-Society Task Force on Colorectal Cancer," The American Journal of Gastroenterology, vol. 97, no. 6, pp. 12961308, 2002.

[12] F. Aslinia, L. Uradomo, A. Steele, B. D. Greenwald, and J.-P. Raufman, "Quality assessment of colonoscopic cecal intubation: an analysis of 6 years of continuous practice at a University hospital," The American Journal of Gastroenterology, vol. 101, no. 4, pp. 721-731, 2006.

[13] F. Froehlich, V. Wietlisbach, J.-J. Gonvers, B. Burnand, and J.-P. Vader, "Impact of colonic cleansing on quality and diagnostic yield of colonoscopy: The European Panel of Appropriateness of Gastrointestinal Endoscopy European Multicenter Study," Gastrointestinal Endoscopy, vol. 61, no. 3, pp. 378-384, 2005.

[14] G. C. Harewood, V. K. Sharma, and P. de Garmo, "Impact of colonoscopy preparation quality on detection of suspected 
colonic neoplasia," Gastrointestinal Endoscopy, vol. 58, no. 1, pp. 76-79, 2003.

[15] C. A. Burke and J. M. Church, "Enhancing the quality of colonoscopy: the importance of bowel purgatives," Gastrointestinal Endoscopy, vol. 66, no. 3, pp. 565-573, 2007.

[16] H. J. Nuss, D. L. Williams, J. Hayden, and C. R. Huard, "Applying the social ecological model to evaluate a demonstration colorectal cancer screening program in Louisiana," Journal of Health Care for the Poor and Underserved, vol. 23, no. 3, pp. 1026-1035, 2012.

[17] S. S. Grubbs, B. N. Polite, J. Carney Jr. et al., "Eliminating racial disparities in colorectal cancer in the real world: it took a village," Journal of Clinical Oncology, vol. 31, no. 16, pp. 19281930, 2013.

[18] J. A. Wilschut, J. D. F. Habbema, M. E. van Leerdam et al., "Fecal occult blood testing when colonoscopy capacity is limited," Journal of the National Cancer Institute, vol. 103, no. 23, pp. 17411751, 2011.

[19] US Department of Health and Human Services 2010, http://healthypeople.gov/2020/about/disparitiesAbout.aspx.

[20] S. Agrawal, A. Bhupinderjit, M. S. Bhutani et al., "Colorectal cancer in African Americans," The American Journal of Gastroenterology, vol. 100, no. 3, pp. 515-524, 2005.

[21] US Census Bureau 2012, http://www.census.gov/.

[22] O. G. Dominic, T. McGarrity, M. Dignan, and E. J. Lengerich, "American College of Gastroenterology guidelines for colorectal cancer screening 2008," The American Journal of Gastroenterology, vol. 104, no. 10, pp. 2626-2627, 2009.

[23] American Cancer Society 2013, http://www.cancer.org/cancer/ colonandrectumcancer/moreinformation/colonandrectumcancerearlydetection/colorectal-cancer-early-detection-acsrecommendations.

[24] G. Abuksis, M. Mor, N. Segal et al., "A patient education program is cost-effective for preventing failure of endoscopic procedures in a gastroenterology department," The American Journal of Gastroenterology, vol. 96, no. 6, pp. 1786-1790, 2001.

[25] A. Kakkar and B. C. Jacobson, "Failure of an internet-based health care intervention for colonoscopy preparation: a caveat for investigators," JAMA Internal Medicine, vol. 173, no. 14, pp. 1374-1376, 2013.

[26] X. Liu, H. Luo, L. Zhang et al., “Telephone-based re-education on the day before colonoscopy improves the quality of bowel preparation and the polyp detection rate: a prospective, colonoscopist-blinded, randomised, controlled study," Gut, vol. 63, no. 1, pp. 125-130, 2014.

[27] B. Lebwohl, A. I. Neugut, E. Stavsky et al., "Effect of a patient navigator program on the volume and quality of colonoscopy," Journal of Clinical Gastroenterology, vol. 45, no. 5, pp. e47-e53, 2011.

[28] US Cancer Statistics Working Group 2013, Accessed at U.S. Department of Health and Human Services Centers for Disease Control and Prevention and National Cancer Institute, http://apps.nccd.cdc.gov/uscs/. 


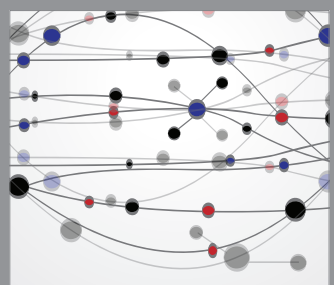

The Scientific World Journal
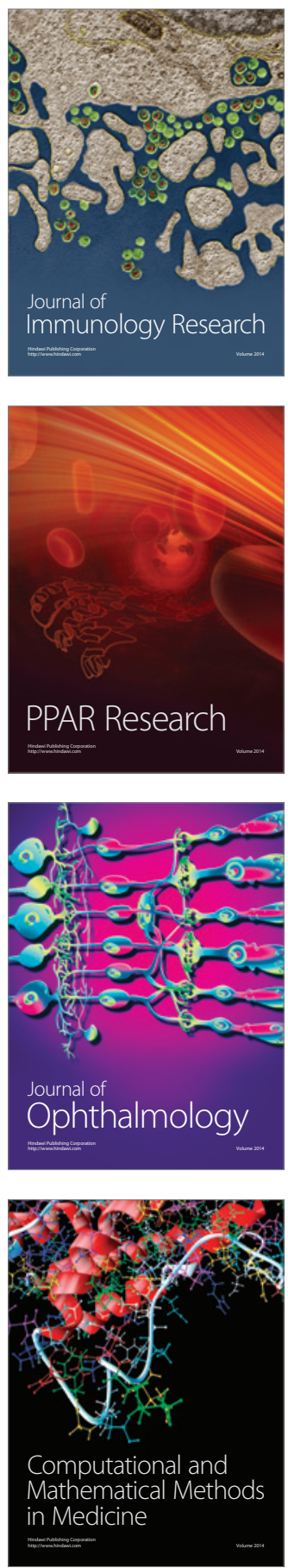

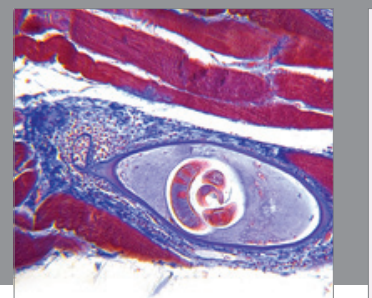

Gastroenterology

Research and Practice
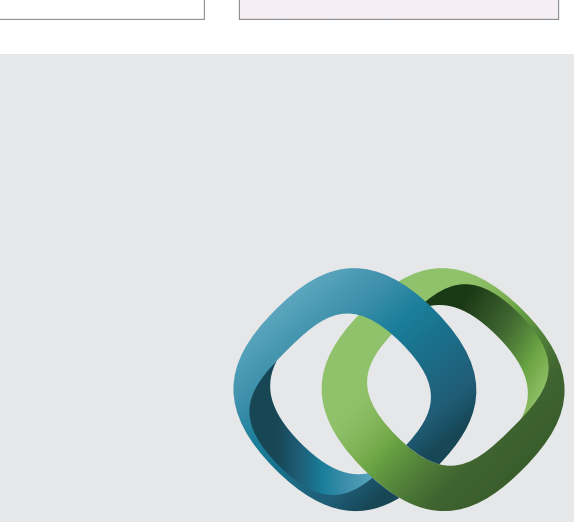

\section{Hindawi}

Submit your manuscripts at

http://www.hindawi.com
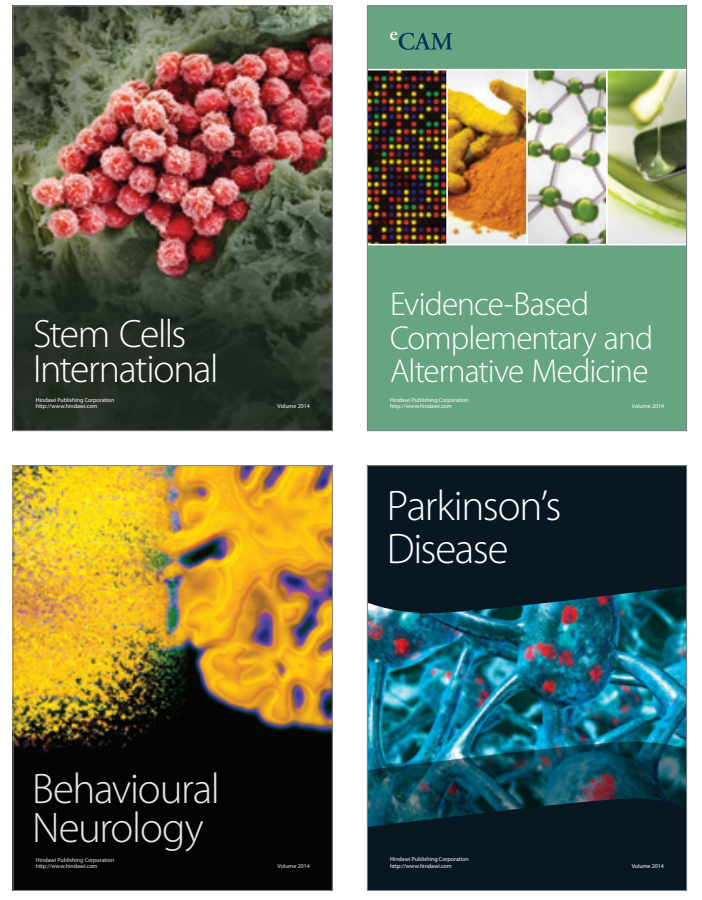
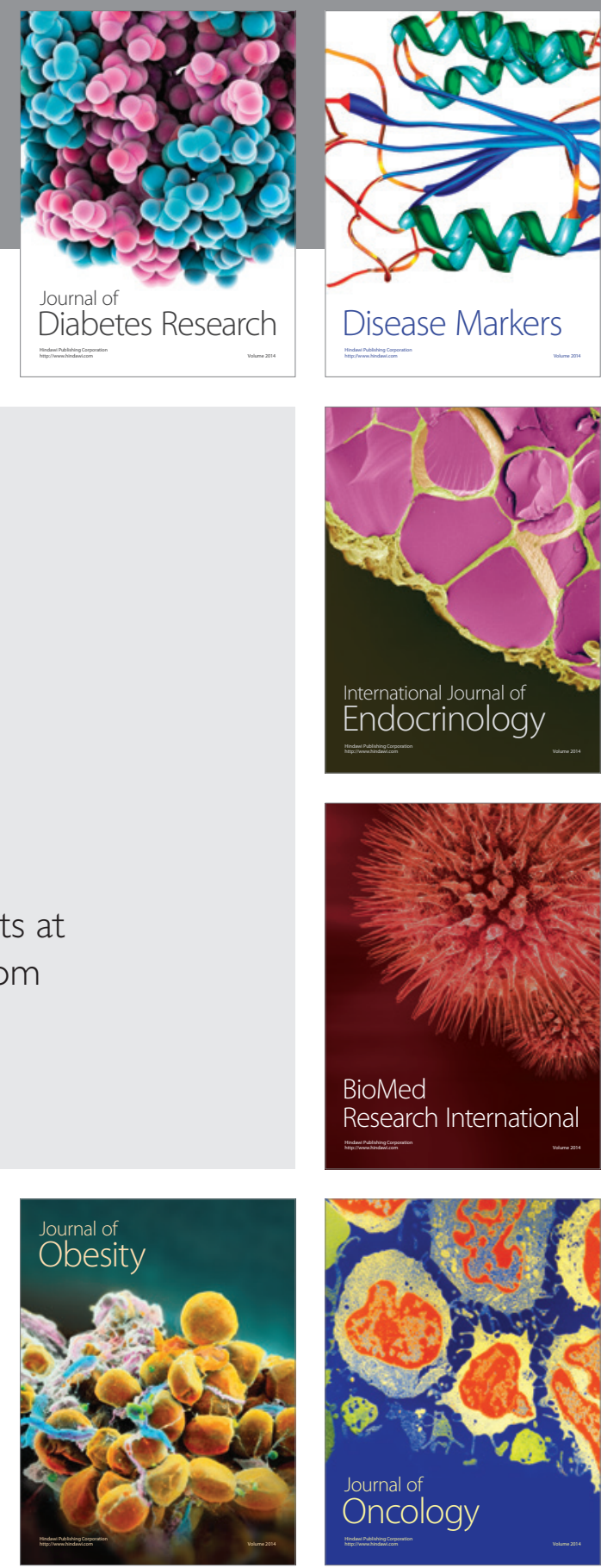

Disease Markers
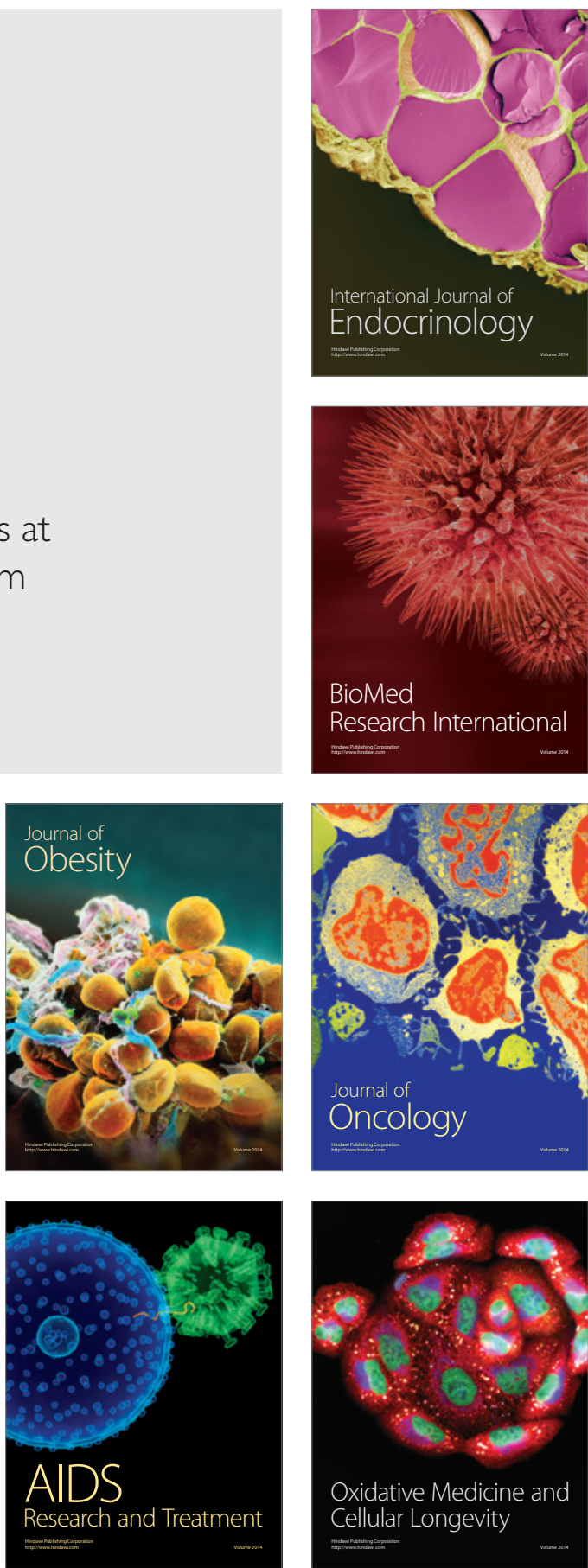